\title{
Cesare Beccaria, Des délits et des peines / Dei delitti e
} delle pene

Introduction, traduction et notes de Philippe Audegean, texte italien établi par Gianni Francioni, Lyon, ENS Éditions, « La croisée des chemins », 2009, 448 p., ISBN 978-2-84788-149-3, $34 €$

\section{Sébastien Annen}

\section{OpenEdition}

12 Journals

\section{Édition électronique}

URL : https://journals.openedition.org/ahrf/11815

DOI : $10.4000 /$ ahrf. 11815

ISSN : 1952-403X

Éditeur :

Armand Colin, Société des études robespierristes

Édition imprimée

Date de publication : 1 juin 2010

Pagination : 246-247

ISBN : 978-2-200-92632-8

ISSN : 0003-4436

Référence électronique

Sébastien Annen, " Cesare Beccaria, Des délits et des peines / Dei delitti e delle pene », Annales historiques de la Révolution française [En ligne], 360 | avril-juin 2010, mis en ligne le 01 juin 2013, consulté le 23 avril 2022. URL : http://journals.openedition.org/ahrf/11815 ; DOI : https://doi.org/ 10.4000/ahrf.11815

Ce document a été généré automatiquement le 23 avril 2022.

Tous droits réservés 


\section{Cesare Beccaria, Des délits et des peines / Dei delitti e delle pene}

Introduction, traduction et notes de Philippe Audegean, texte italien établi par Gianni Francioni, Lyon, ENS Éditions, « La croisée des chemins », 2009, 448 p., ISBN 978-2-84788-149-3, $34 €$

\section{Sébastien Annen}

\section{RÉFÉRENCE}

Cesare Beccaria, Des délits et des peines / Dei delitti e delle pene, Introduction, traduction et notes de Philippe Audegean, texte italien établi par Gianni Francioni, Lyon, ENS Éditions, «La croisée des chemins », 2009, 448 p., ISBN 978-2-84788-149-3, $34 €$

1 Cette édition des Délits et des peines offre la version la plus fidèle du texte italien, établie par Gianni Francioni, et une nouvelle traduction française, entreprise par Philippe Audegean. La traduction est encadrée par un important appareil critique : en tête d'ouvrage, une longue introduction sur le contexte et la genèse de l'œuvre; en fin d'ouvrage, des notes précises qui guident la (re)découverte de Beccaria, des tables de concordance entre les principales versions de l'œuvre, une bibliographie exhaustive et enfin un index des noms.

2 L'introduction, organisée en quatre chapitres, n'entend pas proposer une synthèse de la pensée de Beccaria mais inscrire Des Délits et des peines dans son contexte historique. Le premier chapitre rappelle le rôle tenu par Beccaria au sein de l'« académie des Coups de poing " qui réunit, dans les appartements de Pietro Verri (le corédacteur des Délits), la fine fleur de la jeunesse milanaise, en lutte contre l'autorité paternelle et favorable à la monarchie habsbourgeoise.

3 Philippe Audegean reprend dans le chapitre suivant l'essentiel des enquêtes génétiques menées par Gianni Francioni. À l'origine pamphlet philosophique, organisé en deux grands chapitres, et intitulé Delle pene e delitti («Des peines et des délits », 1763), le manuscrit autographe de Beccaria est rapidement réinterprété par Pietro Verri pour en 
faire un traité juridique organisé en 41 paragraphes et désormais intitulé Dei delitti e delle pene ("Des délits et des peines »). C'est cette version largement remaniée qui est pour la première fois éditée en 1764. L'édition définitive de 1766 (la cinquième) est reprise par Beccaria lui-même et s'organise désormais en 47 paragraphes. C'est cette ultime édition qui fait l'objet de la présente traduction. Dans le troisième chapitre, Philippe Audegean revient en détail sur le « détournement de texte» (p. 61) commis par le premier traducteur français de Beccaria : l'abbé Morellet. Cette traduction, qui devient la vulgate de l'œuvre de Beccaria en Europe jusqu'en 1958 ne laisse que dix paragraphes intouchés. À présent intitulée Traité des délits et des peines (1765), l'œuvre connaît une fortune immédiate et inspire surtout la réforme pénale du grand-duc de Toscane en 1786.

4 Le dernier chapitre introductif revient sur les trois lectures possibles du Traité des délits et des peines. La lecture juridique, initiée par Voltaire, isole les deux principes premiers du Traité : celui de modération et celui de rationalité des délits et des peines. À l'origine de la lecture philosophique, Jeremy Bentham s'inspire de Beccaria pour forger sa doctrine utilitariste. Enfin, à l'origine de la lecture historique, deux visions opposées : celle de Franco Venturi (pour qui Beccaria est l'archétype de l'Italien réformateur des Lumières) et celle de Michel Foucault (qui minore l'influence de Beccaria et lui préfère celle de Bentham).

5 C'est donc après une longue et passionnante introduction que l'on peut entrer dans la nouvelle traduction des Délits et des peines, traduction qui se veut résolument littérale. Il s'agit de retrouver Beccaria, par-delà la vulgate déformée de Morellet. On (re)découvre cette pensée qui a tant plu aux contemporains, tant il est vrai que Beccaria eut l'art d'exprimer simplement ce qui était dans l'air du temps. La question centrale qui parcourt Des délits et des peines est celle de savoir ce qu'est une peine juste. Puisant dans Montesquieu, Beccaria entend anéantir l'arbitraire (compris dans son sens péjoratif) : il considère que la liberté est la connaissance des contraintes qui encadrent la sûreté de chacun, quand au contraire l'absence de liberté est la soumission au bon vouloir des autres. D'où l'affirmation de la figure du juge automate : « Pour chaque délit le juge doit faire un syllogisme parfait : la majeure doit être la loi générale, la mineure est l'action conforme ou non à la loi, la conséquence est la liberté ou la peine » (p. 153). Mais un tel système ne peut fonctionner que si les lois constituent un édifice inébranlable et connu de tous.

6 Ce versant mécanique de la pensée de Beccaria ne peut se comprendre sans son versant philanthropique qui affirme le règne d'une justice légitime et impartiale, qui délaisse l'éclat des supplices pour promouvoir un ordre judiciaire plus doux - mais surtout plus rationnel pour être plus efficace. Les lois doivent servir à canaliser les passions en reposent sur une juste proportion des délits et des peines dont la gravité se mesure en fonction du «dommage fait à la nation » (p. 165). Tout ce qui dépasse cet impératif de proportion et de modération utile doit être banni. Beccaria est ainsi l'un des premiers abolitionnistes d'Europe : la peine de mort est « une guerre de la nation contre un citoyen » (p. 229), « un assassinat public» (p. 237). Efficaces parce que modérées, les peines prévues par Beccaria ne sauraient donc tolérer le droit de grâce accordé au souverain. Inutile quand la législation est parfaite, la clémence n'est tolérée qu'au moment de faire la loi, et non au moment de l'exécuter.

7 Ainsi Beccaria peut-il énoncer son théorème final : «[...] pour qu'une peine ne soit pas une violence d'un seul ou de beaucoup contre un citoyen privé, elle doit être 
essentiellement publique, prompte, nécessaire, la moindre possible étant donné les circonstances, proportionnée aux délits, édictée par les lois » (p. 297).

8 Cette nouvelle édition du texte de Beccaria ne peut être que saluée, même si son prix en fait sans doute l'une des éditions critiques les moins abordables pour les bourses estudiantines et même si un index thématique aurait été apprécié. On regrette par ailleurs que Philippe Audegean n'évoque que trop succinctement la postérité de Beccaria, évacuant les débats révolutionnaires en France. En attendant la parution prochaine de la thèse de Philippe Audegean chez Vrin-EHESS, l'historien saura donc judicieusement se tourner vers les travaux de Michel Porret pour pallier ces lacunes.

9 Enfin, aussi intéressante (et actuelle) que soit cette nouvelle traduction de Beccaria, il n'en demeure pas moins que c'est la traduction de Morellet qui constitue toujours la source de référence pour les historiens travaillant sur la fin $\mathrm{du} \mathrm{xVIII}^{\mathrm{e}}$ siècle. Une édition totale de l'œuvre de Beccaria reste donc à faire; elle rassemblerait les trois versions de référence : le manuscrit autographe, l'ultime version remaniée par Beccaria et la «vulgate» de Morellet. Cette édition contenterait certainement autant les philosophes que les juristes et les historiens. 